\title{
The Role of Co-operative Modeling in Healthcare Provision: A Qualitative Study on the Perceptions of Physicians and Nurses
}

\author{
Ayşegül Yıldırım Kaptanoğlu ${ }^{1}$ \\ Trakya University
}

\author{
Idil Yildirim $^{2}$ \\ Trakya University
}

\begin{abstract}
Although physicians and nurses are trying to effectively provide primary healthcare in family practice centers, many other factors, such as management and finance, also play an important role in healthcare provision. Understanding the perception of nurses and physicians concerning healthcare co-operatives in this context is important. Using a random sample, physicians and nurses were interviewed at their work in a primary healthcare center in Edirne, Turkey for a qualitative study. For the quantitative approach, all family physicians and nurses who signed consent forms were invited to join the research. From the interviews, we identified a specific pattern of concepts, which are associated with the co-operative's healthcare facilities and obstacles. Physicians and nurses who work in an Edirne primary healthcare center are not aware and are not sufficiently motivated to provide healthcare via co-operative modeling.
\end{abstract}

Keywords

Co-operatives $\bullet$ Healthcare co-operatives $\bullet$ Physicians $\bullet$ Nurses $\bullet$ Co-operatives Perceptions Scale

1 Correspondence to: Ayşegül Yıldırım Kaptanoğlu (PhD), Health Management Department, Faculty of Health Sciences, Trakya University, Edirne Turkey. Email: aysegulkaptanoglu@gmail.com

2 Department of Business Administration, Labor Economics and Industrial Relations, Faculty of Economics and Administrative Sciences, Trakya University, Edirne Turkey. Email: hukukcuidil@gmail.com

Citation: Yıldırım Kaptanoğlu, A., \& Yildirim, I. (2016). The role of co-operatives modeling in healthcare: A qualitative study of physicians' and nurses' perceptions. Sanitas Magisterium, 2, 141-152. http://dx.doi.org/10.12738/SM.2016.2.0024 
The 21 st century is characterized by the globalization of the economy, which has led to low wages and rapid economic growth. In turn, these generated high demands for healthcare as a result of technological developments in the health sciences. The European social states have implemented a model of healthcare and social insurance development since the Second World War. However, over the past few decades, this has become obsolete and sustainable because of demographic and economic indicators, such as increased life expectancy, participation of women in the workforce, and the need for formal child care. Apart from these new challenges, new policies must be implemented owing to the massive migration and the resulting economic, political, and social vulnerability and tension. Strong downsizing measures in the economy and the growing unemployment problems during global financial crisis after 2008 have also increased social discontent, thus underlining the importance of identifying new approaches to provide social and health security. These new life models require new health and social policy tools.

The co-operative model of health insurance system could play an important and sustainable role in providing health care and social security. The first co-operative was established in 1844 in Rochdale, England (Fairbairn, 1994). The first healthcare co-operative was founded in 1929 by Dr. Michael Shadid in Elk City, Oklahoma, USA (Majumder, 2001; Shadid, 1956). Dr. Shadid built a hospital and created a prepaid insurance plan to provide healthcare based on the assumption that the government's role was to subsidize the poor's enrollment fees. In Another author argued that consumers must manage the business operations, but doctors should remain in control of the professional aspects of healthcare provision (Crowley, 1996).

The co-operative model of healthcare insurance system in welfare capitalist economies has been transformed since the 1980s, on the basis of the perceived insufficiency of the employer-provided social security system. This kind of co-operative can promote economic growth by improving the investment climate and encouraging co-operatives to invest in banking and financial systems. Overall, co-operatives seem to be an alternative to provide healthcare needs at affordable costs (Campos, 2014).

\section{Definition of the Co-operative Model}

A co-operative is defined as a private business organization that is owned and controlled by the people who use its products, supplies, or services. A co-operative is organized horizontally in order to achieve vertical integration in business activities, and its main aim of a co-operative is to meet the specific objectives of its members; hence, it is structured to adapt to the needs of the members. Co-operatives are important 
for promoting the interest of the economically less powerful members of society. Farmers, all types of producers, workers, health services staff, teachers, social care providers, and consumers could better accomplish their business collectively than they could individually. A co-operative is an autonomous association of individuals who voluntarily unite to meet their common economic, social, and cultural needs and demands through an organization that is collectively owned and democratically controlled (Larson, 2009).

\section{Principles of the Co-operative Model}

Three main principles characterize the co-operative model, as shown in Figure 1.

\section{The User-Owned Principle}

\section{The User-Control Principle}

\section{The User-Benefit Principle}

Figure 1. Three main principles of co-operatives.

The people who own and finance this model are the people who are using it. In other words, the people who manage the co-operative are the ones who use the co-operative themselves guided by democratic principles, such as in the selection of its leaders. The purpose of this model is to provide and distribute benefits to its users on the in order to help such users generate returns on their investments.

\section{Seven Other Principles of the Co-operative Model}

The International Co-operative Alliance is a world-wide association. Its main statement, adopted in 1995 (Calkins \& Ngo, 2005; Duyver, Van Houdt, De Lepeleire, Dory, \& Degryse, 2010), contains seven co-operative principles, as denoted below. 


\section{Voluntary and Open Membership}

\section{Democratic Member Control}

\section{Member Economic Participation}

\section{Autonomy and Independence}

\section{Education, Training and Information}

\section{Cooperation Among Cooperatives}

\section{Concern for Community}

Figure 2. Seven principles of the International Co-operative Alliance (n.d.).

Co-operatives can be categorized according to their purpose, but mainly, their members get from and/or provide goods and services to the co-operative. For example, members of healthcare or health insurance co-operatives provide healthcare services and health services insurance from their co-operatives, whereas members of worker co-operatives, such as physicians, nurses, and so on, constitute the labor force. Healthcare staff provide services to the healthcare co-operative members, as well as obtain health services for themselves; for example, members of a health co-operative can buy services from their healthcare co-operative.

\section{Co-operative Movement in a Capitalist Country}

The co-operative movement in a capitalist country can play an important role by enhancing economic growth and quality of life, which can be measured by social indicators (Zak \& Knack, 2001). Leaders of the developing and industrial capitalist societies know that this movement is meant to raise overall standards of healthcare provision. This is a management movement for coping with the uncertainty of industrial capitalism. In fact, some researchers argued that, more than 150 years from now, co-operatives can still serve as an effective way to provide healthcare services in a capitalist economy, which has many identified goals in an increasingly competitive current economy (Kurimoto \& Kumakura, 2016). These co-operatives are also important mechanisms that manager can use to monitor and manage risks for their 
members. Health co-operatives aim to help salary/wage earners and consumers save for their future, although this approach might be difficult for healthcare professionals and patients. Nevertheless, co-operatives always supply an economic stimulus to their group as well.

\section{A New Generation Co-operative Model and Some Examples}

A New Generation Co-operative (NGC) model is a relatively new type of co-operative that became popular in the early- to mid-1990s among producers interested in collectively adding value to their services. This model is especially used in the value-added processing of healthcare commodities. First used in the upper Midwest in the early 1970s, the NGC organizational model has since been adopted by hundreds of new co-operatives across the US (Herman, 2003).

The NGC is not a specific legal structure. Rather, the term "New Generation Co-operative" is used to describe how a firm operates. The term primarily describes the relationship between the firm and its members and how the firm is financed. Compared with traditional co-operatives, in which start-up expenses are minimal and growth is financed through the members' retained earnings, permanent equity to fund an NGC's start-up and ensure its growth is financed through the sale of delivery rights. In turn, these delivery rights represent a member's right to deliver specific types of commodities to the co-operative. In the new model, members benefit in proportion to their use, and nearly all NGCs are democratically controlled through a one member-one vote system.

In the UK, the growing numbers of co-operatives delivering healthcare services demonstrate that there exists a viable alternative to the private shareholder-led supplier model. Meanwhile, social and healthcare co-operatives in Italy are able to formulate an accessible and relatively more simple version in terms of financing with decreased taxes. More than 7000 social care co-operatives are running in Italy (Berry \& Roberts, 1984; Melnyk, 1985). They provide everything from health care for the elderly and disabled, to jobs for ex-criminals. This so-called "social ecosystem" is the second fastest-growing social enterprise in the field of health and social care in Europe. In a way, healthcare co-operatives help promote measures to overcome such a challenge. Collected data can bring health-related and financial benefits for individuals. Each health or social care co-operative consists of paid workers, users and their families, volunteers, and members. Civil society finally has to reflect upon and formulate community solutions to the challenges of social and healthcare provision amidst the changing global conditions. This economy, which is based on mutuality and ethical principles, can also enable the political power that is necessary 
to discuss a new social contract for a new age, such as running co-operative-like businesses in democratic capitalist countries.

Moreover, co-operative modeling in providing health and social care can offer a better future to the young, elderly, and disabled people as well. As memberbased organizations, co-operatives aim to achieve the health and well-being of its members. They play a pivotal role in providing care for the individuals, preventing illness, and ensuring the social well-being of members and/or their dependents, such as their relatives, among others. However, co-operatives must also generate earnings and manage the business just like any other business organization, the only difference is that the "workers" of the co-operative are also shareholders in the same group (Ollila, Nilsson, \& Hess, 2014). Compared with business organizations, in which shareholders, managers, and workers comprise three distinct groups, the co-operative has workers and managers who also happen to be the shareholders of the group. The suppliers of the co-operative can also serve as large shareholders, such as in health co-operatives wherein the physicians gain benefits or in the healthcare co-operatives where the physicians and nurses gain support. The profits of the co-operative are also distributed as dividends, similar to the practice of regular companies, and whatever is left after interest payments [e.g., taxes, capital expenditure (capex), and reserves] is paid out proportionately to the stakeholders (Anderson, Pickens, \& Boumbulian, 1998).

\section{Purpose}

The purpose of the study was to investigate the perceptions and needs of the healthcare co-operatives' health professionals, such as the nurses and physicians, as well as the importance of sustainable health and social care on co-operative management in developing countries, as exemplified by the Kaiser Permanente Co-operative Development Programs.

\section{Method}

The study used a mixed quantitative and qualitative approach. Quantitative methodology was used with a specific scale prepared for this research. Meanwhile, qualitative methodology is considered to be the best approach for this study, because it meets the descriptive nature of the research problems and gives the best picture of the healthcare co-operative staff's perceptions. It states that "qualitative experience depends on qualitative forms of inquiry such as learn to see, hear, and feel." Given that this study is about co-operative staff's perceptions, a qualitative inquiry also best 
fits this framework. Among 130 family physicians and 131 family nurses in Edirne province, $97 \%$ participated in the study.

\section{Ethics}

Ethical approval for the study was obtained from the Social Sciences Ethics Committee of Trakya University. All participants gave informed consent prior to the collection and storing of data.

\section{Research Questions}

Quantitative questions. The Co-operative Perceptions Scale (CPS) is Likert-type scale, which has five response categories with scores ranging from 1 to 5 as follows: (1) strongly disagree, (2) disagree, (3) agree, (4) agree strongly, and (5) not applicable. The scores were transformed into natural logarithms to achieve a better expression of the relative distances in between items. Next, the items were calibrated from the logit metric to a user-friendly 0 to 100 metric $(0=$ lowest activation level, $100=$ highest activation). The overall Rasch person reliability for the Turkish 10-item measure was between .83 (real) and .85 (model). Item reliability was .99 . A total of $45.2 \%$ of the variance in the data was explained by the measures, and with a perfect model fit, this was expected to be $45.4 \%$. The eigenvalue of the first PCA contrast was 2.6 , which corresponded to $12 \%$ of the variance in the data.

All ten items seemed "applicable" and indicated that the scale can be used for all types of health co-operative staff perceptions, although a revision of these items might be necessary in other co-operative types such as agriculture and pharmacy.

Table 1 shows the Quantitative Questionnaire Rotated Factor Matrix. This table contains the rotated factor loadings (factor pattern matrix), which represent how the variables are weighted for each factor as well as the correlation between the variables and the factor. 
Table 1

Rotated Factor Matrix Co-operative Perceptions Scale (CPS)

\begin{tabular}{lcc}
\hline Co-operatives Perceptions Scale (CPS) & 1 & 2 \\
\hline Co-operatives promote healthcare. & .830 \\
\hline Co-operatives help ensure the provision of health insurance. & .751 \\
\hline Co-operatives help to generate labor force demand in healthcare. & .745 \\
\hline Co-operatives improve healthcare quality. & .738 \\
\hline Co-operatives can provide accessible healthcare services & .623 \\
\hline Co-operatives can provide healthcare for the poor people. & .530 \\
\hline Co-operatives help in poverty reduction. & .483 \\
\hline Co-operatives provide sustainable healthcare services. & .450 \\
\hline Co-operatives can contribute to the provision of social insurance to their members. & .391 \\
\hline
\end{tabular}

For orthogonal rotations, such as varimax, the factor pattern and factor structure matrices were the same. The columns under this heading are the rotated factors that are extracted by SPSS 13.00 for Windows. Three factors were extracted, representing those that analysts were most interested in and tried to name. For example, the first factor might be called "Social Dimension of Healthcare Co-operatives." Healthcare provision loaded highly on this dimension. The second factor might be called "Poverty Reduction," because of items such as "reducing economical load in healthcare." The third factor could be named "Healthcare Provision."

\section{Qualitative Questions}

The following qualitative questions were used:

1. What is a co-operative? Who could own the co-operative?

2. Do you have any idea about co-operatives?

3. Do you think co-operatives could work in the provision of health and social care?

4. What are your perceptions of health and social care co-operatives according to your opinion?

5. What will be the perceptions of your patients and relatives about health and social care co-operatives?

As previously mentioned, this study was qualitative and quantitative in design. A pilot study was conducted to test the reliability and validity of the scale. As a result of the pilot study, two questions were removed, and some other questions were modified to increase clarity. Ten questions were accepted. Data were collected from mid-March to mid-June, 2016. On the day of the interviews, the researcher and interviewers introduced themselves to the health staff. Prior to the interviews, the 
researcher addressed the issue of confidentiality by explaining that the participants' names would be coded. Then, the participants were requested to sign a consent form. Each interview lasted for about one hour. An audit trail that included the raw data was established and maintained. After having completed the interviews and questionnaires at 10 randomly chosen family practice centers located in Edirne, the names of the participants were coded for the qualitative study, whereas electronic copies of the scale responses were also generated for the quantitative study. The responses to the open-ended interviews were tabulated based on the frequency of responses. Using SPSS 13.00 for Windows (Release 13.01, SPSS Inc., Chicago, IL, USA) and N-vivo computer based program, quantitative and qualitative scale questionnaires were analyzed based on the descriptive statistics, such as the frequency and percentage of responses.

\section{Results}

Qualitative and quantitative results are presented below. The following summary presents examples of how qualitative data might be shown. Twelve randomly chosen physicians and nurses participated in the qualitative study, whose results are shown in Table 2.

Table 2

Profession, Gender, and Age of the Participants

\begin{tabular}{lcccc}
\hline Profession & \multicolumn{2}{c}{ Gender } & \multicolumn{2}{c}{ Age } \\
\hline Nurse (n:12) & Female & Male & Female & Male \\
\cline { 2 - 5 } & 6 & 6 & $30.06 \pm 2.01$ & $34.62 \pm 3.52$ \\
\hline Physician (n:12) & 6 & 6 & $38.06 \pm 2.83$ & $41.17 \pm 5.64$ \\
\hline
\end{tabular}

For the qualitative research, 12 nurses and 12 physicians were investigated. Participants' profiles were analyzed based on their age, gender, and profession.

To gain a sense of the co-operative's perceptions regarding co-operative principles, five questions were asked. These are listed below.

1. What is a co-operative? Who could own the co-operative?

Physicians and nurses of primary care were interviewed. About $40 \%$ of the physicians and $30 \%$ of the nurses indicated that the co-operative was member-owned. Only 5\% stated that a co-operative is "a place where people of common interests meet to discuss their problems and develop solutions." One physician stated that a co-operative is "the act of uniting people together with specific and common goals."

2. Do you have any idea about co-operatives? 
Data from the interview quote that were important and/or most representative of the research findings included "I do not have any idea about co-operatives. I cannot make even any difference between company business and co-operatives."

3. Do you think co-operatives could work in the provision of health and social care?

The most significant quote was that "they do not think this could work." Only one physician, 45 years of age, stated that "Co-operatives could play an important role with weak populations, including the disabled, elderly, and the mentally ill, and adopt an all-inclusive membership base."

4. What are your perceptions of health and social care co-operatives according to your opinion?

The participants could not answer this question.

5. What will be the perceptions of your patients and relatives about health and social care co-operatives?

The participants could not answer this question.

\section{Results of the Quantitative Data}

The following sociodemographic characteristics of the respondents were analyzed: gender, age, and profession (Table 3 ). The average age was $45.63 \pm 10.56$ years, with the youngest respondent being 25 years old, and the oldest being 57 years old.

Table 3

Participants' Knowledge Score of Co-operatives according to Quantitative Data

\begin{tabular}{lccc}
\hline \multirow{2}{*}{ Knowledge score (\%) } & Total sample & Scale mean & Scale std. deviations \\
\cline { 2 - 4 } & 126 & 54 & 21 \\
\hline Physicians & 63 & 45 & 19 \\
\hline Nurses & 63 & 39 & 18 \\
\hline
\end{tabular}

Table 4

Participants' Co-operative Perceptions Scale (CPS) according to Gender, Mean, and Standard Deviation

\begin{tabular}{lcccc}
\hline & \multicolumn{2}{c}{ Female Scale Points (n:70) } & \multicolumn{2}{c}{ Male Scale Points $(\mathrm{n}=69)$} \\
\cline { 2 - 5 } & Mean & Std. dev & Mean & Std. dev. \\
\hline Scale & 45 & 19 & 54 & 21 \\
\hline Age & 39 & 11 & 42 & 16 \\
\hline
\end{tabular}


Table 5

Participants' Co-operative Perceptions Scale (CPS) according to Gender

\begin{tabular}{lcc}
\hline & Female & Male \\
\cline { 2 - 3 } Gender & 70 & 56 \\
\hline
\end{tabular}

Table 6

Participants' Co-operative Perceptions Scale (CPS) according to Profession

\begin{tabular}{lcc}
\hline & Nurse & Physician \\
\cline { 2 - 3 } Profession & 63 & 63 \\
\hline
\end{tabular}

\section{Results}

Differences in mean values and the t-test for the analysis of data revealed significant differences between the perceptions of nurses and physicians towards the CPS $(t=4.37, p=.002)$ with mean score of 54.19 [standard error of mean $(\mathrm{SEM})=.610$ ] and 56.37 (SEM $=.421)$ respectively. The CPS has two subscales, namely, knowledge and perception. The knowledge mean score is lower than the perception scale among nurses compared with physicians $(t=6.16, p=.001)$ with mean scores of 51.27 (SEM $=.410)$ and $50.28(\mathrm{SEM}=.301)$, respectively. No statistically difference between age and gender was identified.

Rebuilding the CPS infrastructure to measure knowledge and perception is required. The linkage of health co-operative to academics and researchers via a trusted extension agent greatly improved healthcare efficiency and produced new knowledge, which would have been otherwise situated in an innovative primary care center. Ensuring that primary care physicians optimally contribute to the health of the entire population is certainly no less important.

\section{Limitations of the Study}

There are some limitations in this study. First, the findings may have direct relevance only to the 24 nurses and physicians in the qualitative study and the 126 staff who joined the quantitative study. Second, the convenience sample was representative only of the larger family practice center membership in Edirne Province. 


\section{References}

Anderson, R. J., Pickens, S., \& Boumbulian, P. J. J. (1998). Toward a new urban health model: Moving beyond the safety net to save the safety net-Resetting priorities for healthy communities. Urban Health, 75(2), 367-378. http://dx.doi.org/10.1007/BF02345104

Berry, J., \& Roberts, M. (1984). Co-op management and employment. London, UK: ICOM Co-Publ.

Calkins, P., \& Ngo, A. (2005). The impacts of farmer cooperatives on the standard of living of cocoa producing villages in Côte d'Ivoire and Ghana. Canada: Societe de Cooperation pour le Development International. Retrieved from http://socodevi.org/contenu/prospecteur/uploads/ Cocoa-Cooperatives-and-Well-being-20051130.pdf

Campos, R. (2014). Brazil: The work cooperative social security contribution. Retrieved from http:/www.mondaq.com/brazil/x/291190/retirement+superannuation+plans+pensions + schem es/The+Work + Cooperative + Social + Security + Contribution

Crowley, W. (1996). To serve the greatest number: A history of Group Health Cooperative of Puget Sound. Seattle, WA: University of Washington Press.

Duyver, C., Van Houdt, S., De Lepeleire, J., Dory, V., \& Degryse, J. M. (2010). The perception of the clinical relevance of the MDS-Home Care $\subset$ tool by trainers in general practice in Belgium. Family practice, 27(6), 638-643.

Fairbairn, B. (1994). The meaning of Rochdale: The Rochdale pioneers and the co-operative principles (No. 31778). University of Saskatchewan, Centre for the Study of Co-operatives.

Herman, R. (2003). Choice of organizational form in farmer-owned enterprises (Master's thesis, University of Saskatchewan, Saskatoon).

International Co-operative Alliance. (n.d.). What's a co-op? Retrieved from http://ica.coop/en/ whats-co-op/co-operative-identity-values-principles

Kurimoto, A., \& Kumakura, Y. (2016). Emergence and evolution of co-operatives for elderly care in Japan. International Review of Sociology, 26(1), 48-68.

Larson, E. B. (2009). Group Health Cooperative-One coverage-and-delivery model for accountable care. New England Journal of Medicine, 361(17), 1620-1622.

Majumder, M. R. (2001). The ethics of managed care: A pragmatic approach. Bloomington, IN: Indiana University Press.

Melnyk, G. (1985). The search for community: From utopia to a co-operative society (Vol. 96). Montreal, Quebec: Black Rose Books.

Ollila, P., Nilsson, J., \& Hess, S. (2014). Farmers' reactions to the internationalisation of cooperatives. Agricultural and Food Science, 23(4), 291-306.

Shadid, M. (1956). Crusading doctor. Boston, MA: Meador.

Zak, P. J., \& Knack, S. (2001). Trust and growth. The Economic Journal, 111(470), 295-321. 